\title{
Stay-green expression in early generation sorghum [Sorghum bicolor (L.) Moench] QTL introgression lines
}

\author{
B. Kassahun · F. R. Bidinger $\cdot$ C. T. Hash $\cdot$ \\ M. S. Kuruvinashetti
}

Received: 3 November 2008 / Accepted: 19 August 2009 / Published online: 25 December 2009

(C) The Author(s) 2009. This article is published with open access at Springerlink.com

\begin{abstract}
Reduced leaf senescence (stay-green) has been demonstrated to improve tolerance of post-flowering moisture stress in grain sorghum. A number of quantitative trait loci (QTLs) associated with staygreen have been identified in sorghum, to facilitate transfer of this trait into adapted genetic backgrounds. This study reports initial evaluations, in both well watered and post-flowering stress environments, following partial introgression $\left(\mathrm{BC}_{2} \mathrm{~F}_{3} / \mathrm{BC}_{1} \mathrm{~F}_{4}\right.$ generations) of four stable stay-green QTLs (StgB, Stgl, Stg3 and Stg4) from donor parent B35 to senescent variety $\mathrm{R} 16$. The majority of the introgression lines had higher leaf chlorophyll levels at flowering (a distinctive trait of the donor parent) and a greater percentage green leaf area during the latter part of grain filling, than did R 16, indicating that the stay-green QTLs were expressed phenotypically in the R 16 background. None of the QTL introgression lines achieved the same level of stay-green as B35, however.
\end{abstract}

B. Kassahun

College of Agriculture and Veterinary Medicine,

Jimma University, P.O. Box 307, Jimma, Ethiopia

F. R. Bidinger · C. T. Hash ( $₫)$

International Crops Research Institute for the Semi-Arid

Tropics, Patancheru, Hyderabad, Andhra Pradesh 502 324, India

e-mail: c.hash@cgiar.org

M. S. Kuruvinashetti

Department of Biotechnology, University of Agricultural

Sciences, Dharwad, Karnataka 580 005, India
Maintenance of a greater relative green leaf area during the latter half of grain filling was related to a greater relative grain yield in two of three post-flowering moisture deficit environments in which the materials were evaluated $\left(r^{2}=0.34\right.$ in 2004-2005 and $r^{2}=0.76$ in 2005-2006), as was a direct measure of leaf chlorophyll in one of the post-flowering stress environments in which this was measured $\left(r^{2}=0.42\right.$, $P<0.05)$. Thus the study provided useful evidence that the marker-assisted backcross transfer of staygreen QTLs from B35 into an adapted, but senescent background has the potential to enhance tolerance of post-flowering drought stress in sorghum.

Keywords Sorghum bicolor (L.) Moench . Stay-green · QTL introgression · Post-flowering drought tolerance
Abbreviations
BC Backcross
$\%$ GLA Percent green leaf area
MABC Marker-assisted backcross

\section{Introduction}

Sorghum [Sorghum bicolor (L.) Moench] is the fifth most important cereal crop globally after wheat, maize, rice and barley (FAO 2006). Sorghum is unique among the major cereals in that its grain is the staple food grain of the world's poorest and most 
food-insecure people, located primarily in the semiarid tropics. World sorghum grain production was about 57 million metric tons and the total area under sorghum was 42.7 million hectares during 20042005 , of which $\sim 90 \%$ was in developing countries, most of this in the semi-arid areas of Africa and Asia (FAO 2006). In peninsular India, 5.5 million hectares of sorghum are grown following the rainy season, on residual moisture, in a unique production environment that produces high quality grain and stover, but is characterized by increasing moisture stress as the season progresses.

Improving the drought tolerance of sorghum is one of the most important objectives of plant breeders focusing on this crop, to minimize the yield losses resulting from moisture stress, which is a regular feature of most sorghum growing environments. The most damaging drought stress is that which occurs during the post-flowering stage of crop growth (referred to as "terminal drought"). Genotypes sensitive to this type of drought are characterized by premature leaf and plant senescence; stalk collapse and lodging, charcoal rot and reduced grain number and size. In sorghum, the best characterized form of drought tolerance during this stage of crop growth is the so called non-senescence or "stay-green" trait, which is the ability to resist premature plant senescence (retain green leaf area), resist lodging and fill grain normally (Rosenow et al. 1983). When water is limited during the grain-filling period, sorghum genotypes possessing this trait maintain photosynthetically active leaf area better than genotypes that do not possess this trait (Rosenow et al. 1983; McBee 1984; Borrell et al. 2000a, b). Further, along with plant height and flowering time, variation in the stay-green trait is predictive of hybrid grain yield performance in drought-prone Australian sorghum production environments (Jordan et al. 2003).

Stay-green has been proposed to be a consequence of the balance between nitrogen $(\mathrm{N})$ demand by the grain and $\mathrm{N}$ supply from translocation from the vegetative parts of the plant and uptake by the roots during grain filling (Borrell et al. 2000b). It is likely that the senescence of the leaves is triggered by an increased demand for $\mathrm{N}$ from the panicle, as the longevity of a leaf is intimately related to its $\mathrm{N}$ status (Thomas and Rogers 1990). During leaf senescence, amino acids cease to be synthesized, existing protein is degraded and not replaced, and the resultant amino acids are translocated out of the leaf. A considerable proportion of leaf protein is bound in pigment-protein complexes of the photosynthetic apparatus, resulting in the characteristic yellowing of the leaves as these chlorophyll-protein complexes are broken down.

A delayed remobilization of $\mathrm{N}$ from the leaves or remobilization of $\mathrm{N}$ from leaves having a larger pool of $\mathrm{N}$ (both associated with stay-green) would maintain photosynthetic capacity for longer, and therefore carbohydrate supply to the developing grain. Delayed leaf senescence in sorghum has been linked to higher grain yields, particularly in environments in which available water during grain filling is not adequate to support potential transpiration (Borrell et al. 1999, 2000a, b). Borrell et al. (2000b) also reported that stay-green sorghum hybrids produced $47 \%$ more post-anthesis biomass than their counterparts under terminal moisture deficit conditions.

Results from breeding programs in the USA (Rosenow et al. 1983) suggest that crop improvement under water-limited conditions are more effective, if drought tolerance traits such as stay-green are selected for in addition to grain yield. However, phenotypic selection for stay-green is not simple as the trait is complex (van Oosterom et al. 1996) and its expression is affected both by the degree of stress during grain filling and by the sink size (nitrogen demand) of the panicle. The trait is likely to be more easily manipulated using a marker-assisted breeding approach, using as selection criteria specific alleles at molecular loci linked to genomic regions contributing to the stay-green trait (i.e., quantitative trait loci = QTLs), identified in carefully managed, replicated, multi-environment tests. The work of different groups has led to a better understanding of the inheritance of stay-green (Walulu et al. 1994; van Oosterom et al. 1996; Tuinstra et al. 1997), to the mapping of QTLs associated with postflowering drought tolerance in sorghum (Tuinstra et al. 1996, 1998; Crasta et al. 1999; Tao et al. 2000; $\mathrm{Xu}$ et al. 2000b; Subudhi et al. 2000; Kebede et al. 2001; Sanchez et al. 2002; Haussmann et al. 2002) and identification of markers linked to these QTLs (Hash et al. 2003; Harris et al. 2007).

The ability to manipulate complex traits such as drought tolerance via MABC (marker-assisted backcrossing) makes it much easier to introduce such a new trait into a breeding program. MABC increases efficiency in introgression programs by permitting simultaneous foreground selection for introgression 
of an exotic allele with potential to improve performance for a trait of interest and background selection for the desired recurrent parent genotype in other genomic regions. While considerable work has been done on the identification of stay-green genotypes, mapping of QTLs associated with the trait and identification of molecular makers linked to these QTLs (references above); there are few reports on the actual transfer of these QTLs into elite cultivars and the assessment of the expression and consequences of the stay-green trait in different backgrounds.

The International Crops Research Institute for the Semi-Arid Tropics (ICRISAT) has initiated a large-scale marker-assisted backcrossing program for the stay-green component of terminal drought tolerance in sorghum. As a part of this program, the present study was conducted to evaluate the initial introgression lines in terms of stay-green expression (maintenance of green leaf area and chlorophyll content) and its consequences for grain filling and grain yield, under post-flowering drought stress conditions.

\section{Materials and methods}

The parental lines used for this backcross program were B35 (donor parent) and R 16 (recurrent parent). $\mathrm{B} 35$ is a $\mathrm{BC}_{1}$ derivative of landrace germplasm accession IS 12555, which is a durra sorghum from Ethiopia (Rosenow et al. 1983). It is the best characterized source of stay-green for terminal drought tolerance in sorghum (Rosenow et al. 1983), and appears to have Type A stay-green-delayed onset of leaf senescence (Thomas and Smart 1993; Thomas and Howarth 2000). B35 is extremely dwarf (three dwarfing genes), has non-tan plant color, and produces awned semi-open panicles having grains with a yellow pericarp and thick mesocarp. It has a low grain yield under the conditions of this experiment, due to its short plant height, small panicle size, and low grain number. A number of stay-green QTLs have been identified by different research groups based on RIL populations derived from crosses involving this line or its derivatives (Tuinstra et al. 1996; Crasta et al. 1999; Xu et al. 2000b; Subudhi et al. 2000; Sanchez et al. 2002). The recurrent parent, $\mathrm{R} 16$, is a released, high yielding but very senescent, post-rainy (rabi) season variety.
Four QTLs (StgB, Stg1, Stg3 and Stg4) associated with the stay-green trait and located on three linkage groups were selected as the targets for markerassisted backcrossing (MABC). The donor parent was crossed to the recurrent parent and the resulting $\mathrm{F}_{1}$ plants were backcrossed to the recurrent parent to generate the $\mathrm{BC}_{1} \mathrm{~F}_{1}$ population. Some of the $\mathrm{BC}_{1} \mathrm{~F}_{1}$ plants were selfed and others were backcrossed to the recurrent parent to generate $\mathrm{BC}_{1} \mathrm{~F}_{2}$ and $\mathrm{BC}_{2} \mathrm{~F}_{1}$ seeds, respectively. The $\mathrm{BC}_{1} \mathrm{~F}_{2}$ and $\mathrm{BC}_{2} \mathrm{~F}_{1}$ plants grown from these seeds were selfed and the resulting $\mathrm{BC}_{1} \mathrm{~F}_{3}$ and $\mathrm{BC}_{2} \mathrm{~F}_{2}$ plants were screened for donor alleles at marker loci flanking the QTL regions and recurrent parent alleles in non-QTL regions. Based on the genotypic data, plants homozygous for the donor alleles in one or more of the stay-green QTLs regions and for recurrent parent alleles in the non QTLs regions were selected and selfed to produce $\mathrm{BC}_{1} \mathrm{~F}_{4}$ and $\mathrm{BC}_{2} \mathrm{~F}_{3}$ progenies. Nine such QTL introgression lines were evaluated in this experiment: three $\mathrm{BC}_{2} \mathrm{~F}_{3}$ progenies (RSG 04001, RSG 04002 and RSG 04003) with a single QTL $(\operatorname{Stg} B)$ and six $\mathrm{BC}_{1} \mathrm{~F}_{4}$ progenies (RSG 04004, RSG 04005, RSG 04007, RSG 04009, RSG 04011 and RSG 04014) with multiple QTLs (two or more of StgB, Stg1, Stg3 and Stg4).

These nine stay-green QTL introgression lines (plus the parents and various checks) were evaluated during the 2004-2005 and 2005-2006 post-rainy seasons at the ICRISAT research station at Patancheru, India. The evaluations were done in the post-rainy sorghum cropping season (October to February), in which crops growing largely on stored soil moisture predictably experience moderate but prolonged terminal drought stress during grain filling. This is an ideal environment for evaluating the stay-green trait (Mahalakshmi and Bidinger 2002). The field used for the experiment-a shallow $(75 \mathrm{~cm})$ Vertic Inceptisol, overlying porous gravelly subsoil—does not contain enough water for an approximately 120-day crop to reach maturity. The evaluations included a supplementally-irrigated environment and one (2004-2005) or two (2005-2006) "dryland" environments that were managed (below) to exhaust readily available soil moisture at different times. Trial entries in all environments were sown into a full soil profile and given irrigation at 25-30 days after emergence to rewet the profile and assure secondary root penetration. This was done by furrow in 2004-2005 (to refill the soil profile) and by sprinkler in 2005-2006 (to 
simply wet the upper part of the profile). The 20042005 dryland environment and the 2005-2006 earlyonset stress dryland environment received no further irrigation; the 2005-2006 late-onset stress environment received another light sprinkler irrigation of $25 \mathrm{~mm}$ at 54 days after emergence. The supplementally-irrigated environments received furrow irrigations at flowering and mid grain-filling stages, to provide sufficient water to allow the crop to complete grain filling without experiencing serious drought stress. The dryland environments completed grain filling on whatever moisture was stored in the soil at flowering. During the 2004-2005 experiment there was $50 \mathrm{~mm}$ of rainfall in late January, but the crop was nearing maturity and it had little effect on leaf senescence; there was no appreciable rainfall during the course of the 2005-2006 experiment. The crop was well fertilized in 2004-2005 $(90 \mathrm{~kg} \mathrm{~N}$ and $42 \mathrm{~kg}$ $\left.\mathrm{P}_{2} \mathrm{O}_{5} \mathrm{ha}^{-1}\right)$ and moderately fertilized $(60 \mathrm{~kg} \mathrm{~N}$ and $17 \mathrm{~kg} \mathrm{P}_{2} \mathrm{O}_{5} \mathrm{ha}^{-1}$ ) in 2005-2006. Shoot fly (weekly sprays of cypermethryn for the first 4 weeks after emergence) and stem borer (whorl application of carbofuran at 4 weeks after emergence) were controlled chemically; leaf rust was controlled by weekly Dithane M 45 sprays in 2004-2005, but was not a problem in 2005-2006.

Plots for the trials were 4 rows $\times 9 \mathrm{~m}$ (2004-2005) or $\times 4 \mathrm{~m}(2005-2006)$ in a 4 (blocks per rep) $\times 5$ (entries per block) alpha design with 4 replications in each moisture environment. An area of the two center rows $\times 3 \mathrm{~m}$ was reserved in each year for a final crop harvest (grain and stover yields and yield components). Three plants per plot were tagged at flowering and the areas of leaves $1-6$ (where leaf $1=$ the flag leaf) were estimated from leaf length and width measurements, based on an experimentally determined ratio of leaf area to leaf length $\times$ width for each genotype. The percent green leaf area (\% GLA) of each leaf of each of the tagged plants was estimated visually on a weekly basis from flowering to harvest. Weekly weighted (by leaf size) average GLA per plant was calculated and averaged first on a plot basis and then on a genotype basis. Logistic curves were fit to the genotype $\times$ date $\%$ GLA means using the logistic curve fitting routine of Genstat (version 9), and the fitted curves were used to compare genotype senescence patterns and to predict GLA at key times during the grain-filling period (Mahalakshmi and Bidinger 2002).
Chlorophyll content (SPAD value) of the leaves was measured in the early stress environment of the 2005-2006 trial using a Minolta Chlorophyll Meter, SPAD-502 (Minolta Camera Co. Ltd.) as described by Dwyer et al. (1991). The SPAD values were taken at the middle of the leaf lamina of the second and fourth leaves from the top from three plants per plot (same plants that were used for visual scoring), averaged on a plot basis for each leaf. SPAD values provide an indication of the relative amount of total chlorophyll present in plant leaves, based on the amount of light transmitted by the leaf (area $2 \times 3 \mathrm{~mm}$ ) in two wavelength regions in which the absorption of chlorophyll is different. Higher SPAD values represent higher total chlorophyll contents and the arbitrary SPAD values can be translated to the actual value of total chlorophyll per unit area $\left(\mathrm{mg} \mathrm{cm}^{-2}\right)$ using the equation; chlorophyll content $=$ SPAD value $\times 0.003-0.048$ (Xu et al. 2000a).

Genotype differences in \% GLA at three times during the grain-filling period were analyzed by dividing the five trials into supplementally-irrigated control and post-flowering stress environments (with individual trials nested within environment), and using the genotype $\times$ trial (within environment) mean square as an error term to test the environment, trial (within environment), genotype and genotype $\times$ environment mean squares in a conventional analysis of variance (Genstat ver. 9). As the interaction of genotype and moisture environment was not significant, genotype data for \% GLA were reported as the means across environments. Genotype differences in SPAD reading were analyzed by ReML analysis, with genotype, leaf number and date of reading (as days after flowering) as fixed effects and replication and block within replication as random factors (Genstat ver. 9). Genotype means were reported across leaves (although genotype $\times$ leaf number interactions were significant), for all dates of reading.

\section{Results and discussion}

Leaf senescence patterns

Leaf senescence patterns (weighted \% GLA versus days after flowering) followed the typical logistic curve pattern of an initial plateau value following flowering, a prolonged period of senescence during 

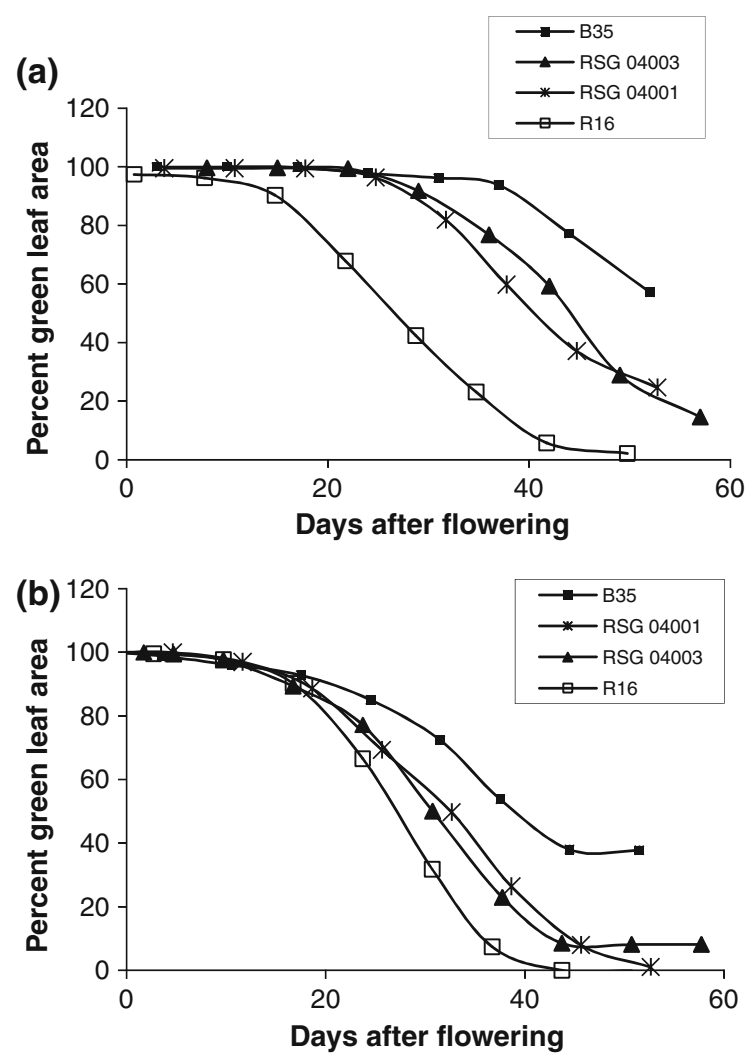

Fig. 1 Leaf senescence patterns for R 16, B35, RSG 04001 and RSG 04003 in a the supplementally-irrigated control environment, 2004-2005 and b the late-onset stress dryland environment, 2005-2006

grain filling, and a final plateau at maturity, as typified by the recurrent parent R 16 (Fig. 1a, b). However, the specific characteristics of the general pattern (time of onset of the decline in \% GLA and the rate of decline) were affected by both the moisture environment during grain filling and by genotype. In the nonstressed environment, genotypic differences in the time of onset of senescence were very marked, from 15 days after flowering in the senescent parent $\mathrm{R} 16$, until about 40 days in the stay-green parent B35 (Fig. 1a). The majority of QTL introgression lines were intermediate between their parents, with loss of $\%$ GLA beginning about 25 days after flowering (e.g. RSG 04001 and 04003, Fig. 1a). There were no evident differences in the rate of decline in \% GLA among genotypes in the absence of stress, with the result that the final \% GLA at maturity was mainly a function of the time of onset of stress. The \% GLA at maturity of most of QTL introgression lines was thus intermediate between the donor and recurrent parents.
In contrast, in the post-flowering drought stress environments the decline in \% GLA began about 15 days after flowering in all genotypes, but the rates of decrease varied among genotypes (Fig. 1b). B35 had the slowest rate of decrease, and thus reached maturity with a substantial percent green leaf area (about 40\%). R 16 had the greatest rate of leaf senescence under stress and consequently reached zero \% GLA well before crop maturity. Most of the QTL introgression lines were again intermediate, but still had effectively no green leaf left at maturity. From these comparisons, it appears that post-flowering moisture stress overrides the normal (in the absence of stress) differences in time of onset of stress between a stay-green and a senescent line, but that the stay-green trait still results in a reduced rate of senescence, and a consequent greater \% GLA during the critical late stages of grain filling when final grain size is determined. Van Oosterom et al. (1996) concluded that the inheritance of onset of senescence was additive whereas the inheritance of the rate of senescence was completely dominant for the slow rate over a fast rate. If it can be assumed that the presence of a partial complement of the total B35 set of stay-green QTLs in the introgression lines is analogous to a genetically heterozygous condition for the full complement of B35 genes contributing to this trait, the conclusions of van Oosterom et al. (1996) describe our findings on the differences in onset of leaf senescence in the absence of stress in this data set (Fig. 1a), but not the differences in rates of senescence under stress (Fig. 1b). Green leaf area duration, being the sum of an additively and a dominantly inherited trait, displayed partial dominance for a long green leaf area duration in the data of van Oosterom et al. (1996). Walulu et al. (1994) also suggested that a major gene in B35 influencing leaf area duration exhibits varied levels of dominant gene action, depending on the evaluation environment. We did not calculate leaf area duration in this study, but an inspection of the \% GLA curves in Fig. 1 suggests greater expression of the stay-green trait in the supplementally-irrigated control environment than in the more severe postflowering stress environments.

If leaf senescence is driven by a demand for nitrogen from the developing grain (as discussed in the introduction) then the senescence patterns of B35 under the two moisture environments suggest that it may continue to take up soil nitrogen after flowering 
as long as soil water is plentiful, and thus delay senescence until well into grain filling; but that when soil water supplies are limited, soil $\mathrm{N}$ uptake is reduced and it begins breaking down chlorophyll and translocating $\mathrm{N}$ from its leaves much earlier during grain filling. However, its slower rate of leaf senescence (compared to that of R 16) even when soil water supply is limited suggests that it either still accesses some soil $\mathrm{N}$ or that it has a greater $\mathrm{N}$ pool in the vegetative parts of the plant to draw on, reducing the demand from the leaves and delaying senescence. There are reports in the literature of both effects in stay-green hybrids. For example, Rajcan and Tollenaar (1999) found that the stay-green maize hybrid Pioneer 3902 accumulated $60 \%$ of total plant $\mathrm{N}$ after silking, compared to only $40 \%$ in the case of senescent hybrid Pride 5. Borrell and Hammer (2000) reported that stay-green sorghum hybrids had a higher percentage of total plant $\mathrm{N}$ in their leaves compared with their senescent counterparts, from as early as 27 days after emergence. This resulted in a higher specific leaf $\mathrm{N}$ in stay-green genotypes at anthesis, mid grain filling and maturity, which they associated with the reduced rates of leaf senescence.

The analysis of variance of the \% GLA for the full data set indicated significant effects of moisture environment, trial within environment and genotype, but (apart from the crop maturity stage) no significant genotype $\times$ environment effects (Table 1 ), which is consistent with the examples in Fig. 1. Differences between grain-filling moisture environments, based on predicted \% GLA values from the fitted logistic equations, were very clear as \% GLA at mid grain filling was approximately $82 \%$ in the supplementally-irrigated

Table 1 Mean squares for genotype, moisture environment and genotype $\times$ moisture environment effects on percent green leaf area at mid grain filling, 2/3 grain filling and physiological maturity for stay-green introgression lines from supplementallyirrigated and post-flowering stress dryland environments

\begin{tabular}{lrrrr}
\hline $\begin{array}{l}\text { Source of } \\
\text { variation }\end{array}$ & $d f$ & \multicolumn{3}{l}{ Percent green leaf area } \\
\cline { 2 - 5 } & & $\begin{array}{l}\text { Mid grain } \\
\text { filling }\end{array}$ & $\begin{array}{l}\text { 2/3 grain } \\
\text { filling }\end{array}$ & Maturity \\
\hline Environment & 1 & $16,408^{* * *}$ & $26,874 * * *$ & $6,718^{* * *}$ \\
Trial (environ) & 3 & $525 * * *$ & $1,326^{* * *}$ & 33 \\
Genotype & 10 & $596^{* * *}$ & $843^{* *}$ & $743^{* * *}$ \\
Geno $\times$ environ & 10 & 46 & 130 & $250^{* * *}$ \\
\hline
\end{tabular}

*** $P<0.001 ; * * P<0.01$
Table 2 Percent green leaf area at mid grain filling, 2/3 grain filling and physiological maturity by moisture environment and R 16 stay-green QTL introgression line

\begin{tabular}{lccc}
\hline & $\begin{array}{l}\text { Mid grain } \\
\text { filling }\end{array}$ & $\begin{array}{l}\text { 2/3 grain } \\
\text { filling }\end{array}$ & $\begin{array}{l}\text { Physiological } \\
\text { maturity }\end{array}$ \\
\hline Environments & & & \\
Irrigated control & 82.0 & 60.7 & 25.9 \\
Post-flowering stress & 46.7 & 15.6 & 3.3 \\
S.e.d. & 2.31 & 2.21 & 2.17 \\
Genotypes & & & \\
B35 & 82.0 & 65.0 & 45.8 \\
R 16 & 45.2 & 17.0 & 2.8 \\
RSG 04001 & 67.4 & 40.6 & 7.8 \\
RSG 04002 & 65.6 & 34.8 & 10.2 \\
RSG 04003 & 72.8 & 43.8 & 19.2 \\
RSG 04004 & 54.8 & 26.8 & 9.0 \\
RSG 04005 & 55.8 & 33.0 & 7.6 \\
RSG 04007 & 55.4 & 26.2 & 7.6 \\
RSG 04009 & 56.2 & 24.8 & 2.4 \\
RSG 04011 & 50.0 & 24.0 & 6.8 \\
RSG 04013 & 63.6 & 34.2 & 16.4 \\
S.e.d. & 5.31 & 5.07 & 4.98 \\
RSG > R 16 & 6 & 5 & 2 \\
\hline RSG $>$ R 16 is the number of QTL introgression lines that are \\
significantly $(P<0.05)$ greater than R 16 \\
\end{tabular}

control environment versus $47 \%$ in the stress environment and $26 \%$ at physiological maturity in the control environment versus $3 \%$ in the stress environment (Table 2). Similarly, there were large differences between the stay-green donor and recurrent parents (Table 2). B35 had an average of $82 \%$ GLA at mid grain filling (95\% GLA in the control and $75 \%$ in the stress), and an average $46 \%$ GLA at physiological maturity (70\% GLA in the control and 23\% GLA in the stress, data not presented). R 16, in contrast had only an average of $45 \%$ GLA at mid grain filling (68\% in the control and $30 \%$ in the stress) and only $3 \%$ GLA at physiological maturity (4\% in the control and $0 \%$ GLA in the stress).

The stay-green QTL introgression lines were on average generally intermediate between the parents, maintaining an average (across moisture environments) of $60 \%$ GLA at mid grain filling (range of 50$73 \%$ ) and $10 \%$ GLA at maturity (range of $2-20 \%$, Table 2). In the individual moisture treatments, the QTL introgression lines at mid grain filling had 
70-94\% GLA versus 68\% GLA in R 16 in the control environment and between 36 and 59\% GLA in the stress environment versus 30\% GLA for R 16 (data not presented). Similar figures for physiological maturity in the control for the introgression lines were 5-48\% GLA versus 4\% GLA for R 16, and 0-3\% GLA in the stress environment versus 0\% GLA for R 16. On average, six of the nine QTL introgression lines had a significantly $(P<0.05)$ higher \% GLA than R 16 at mid grain filling, five of the nine at $2 / 3$ grain filling and two of the nine at maturity (Table 2). The best of the introgression lines for the first twothirds of grain filling were RSG 04001 and RSG 04003, with $>40 \%$ mean GLA at 2/3 grain filling, and the best during the last third of grain filling were RSG 04002, RSG 04003 and RSG 04013, with 10-20\% mean GLA at maturity (Table 2).

The finding that most of the $\mathrm{R} 16$ derivatives were more stay-green than R 16 during the first two-thirds of grain filling, indicates that the transfer of one or more putative stay-green QTLs into R 16 did reduce leaf senescence in most of the backcross derivatives. So it appears that the introgressed stay-green QTLs were well expressed phenotypically. Ultimately, it would be useful to assess the contribution of individual QTLs transferred from B35 to R 16. While most of the derived lines, which were expected to have only one to three stay-green QTLs, were less senescent than R 16 , none approached the degree of non-senescence of B35. The higher degree of stay-green in B35 could be a result of either an additive effect of multiple QTLs, a direct effect of specific QTLs, or a result of complex interactions between favorable alleles at these QTLs, effects that were not replicated in any of the individual derivatives. Sanchez et al. (2002), reporting the phenotypic contribution of QTLs to the expression of stay-green, indicated that each QTL had a different level of contribution to the expression of the trait, and that the combined effects of the QTLs enhanced stay-green expression although they were not fully additive. They reported that $S t g 1, S t g 2, S t g 3$, and Stg4 individually explained 17.1, 24.5, 10.7, and $11.1 \%$ of the phenotypic variance of the stay-green expression, respectively, whereas the four QTLs together explained $42.5 \%$ of the phenotypic variance, and but did not consider the $\operatorname{Stg} B$ QTL that expressed well in single-QTL introgression lines RSG 04001, RSG 04002, and RSG 04003 in the present study. This suggests that it may be necessary to pyramid a number of QTLs in the background of a highly senescent line such as R 16, in order to achieve the level of expression of non-senescence present in B35. However, the expression of a stay-green QTL in a different (R 16) genetic background may not be the same as in B35 background, either because of different kinds of gene interactions or because of a greater sink demand for $\mathrm{N}$ in the higher yielding background. This latter effect would mean that it would be very difficult to achieve the characteristically late-onset and/or slow rate of leaf senescence of B35 (with its relatively small sink size) in a background with a greater sink size.

Finally, the lack of a genotype $\times$ moisture interaction for \% GLA suggests that the QTLs involved are expressing as a constitutive trait and not a response to stress, at least in a highly senescent genetic background in the post-rainy season, stored soil moisture environment used in these evaluations. As such, it is likely to be simpler to manage in a breeding program, as specific moisture environments may not be required to assess the expression of the trait. In fact, in this example, the expression of the trait was easiest to assess in the supplementally-irrigated post-rainy season environment (Fig. 1a).

Leaf chlorophyll content

In order to determine if the introgression of the B35 stay-green QTL into the R 16 background also affected chlorophyll concentration, we made regular SPAD measurements on leaves two and four of the introgression lines in the 2005-2006 early-onset stress environment, from flowering to about 35 days after flowering, when values in $\mathrm{R} 16$ declined to near zero under the severe stress of this trial.

The changes in \% GLA and SPAD reading of leaf two over the first 30 days of grain filling were very similar, in terms of both the onset and rate of decline of both parameters (Fig. 2a, b). The apparent earlier decline in \% GLA compared to that of the SPAD reading is likely an artifact of the way in which the measurements were made. The visual estimate of $\%$ GLA includes the whole leaf, including the leaf tip and margins where senescence usually begins, whereas the SPAD readings were taken in several positions in the center of the leaf. The most noticeable difference between the two measurements was the differences among genotypes both before and after the onset of senescence in the case of the SPAD readings, 

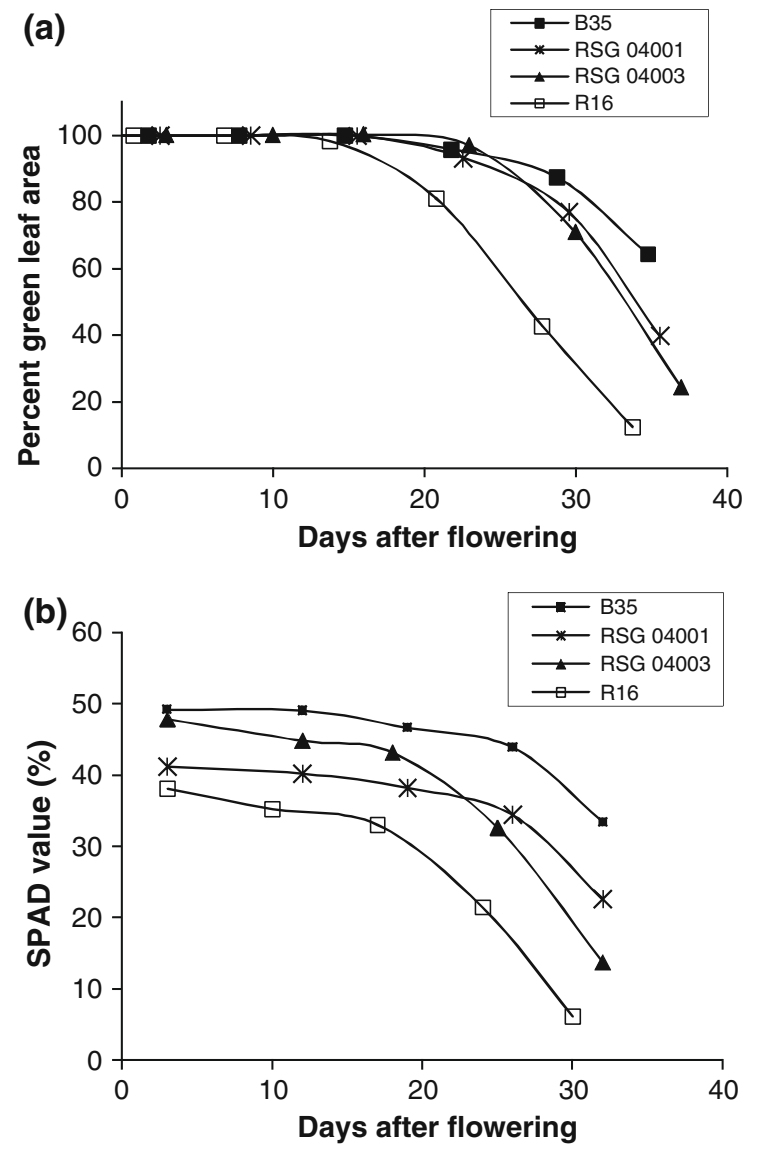

Fig. 2 Comparison of changes in a percent green leaf area and b SPAD readings for leaf two of R 16, B35, RSG 04001, and RSG 04003 in the early-onset stress dryland environment, 2005-2006

where differences were only evident after the onset of senescence in the case of \% GLA. Not only did the onset of the decline in the SPAD readings begin later in B35 compared to R 16, but the B35 values were $\sim 25 \%$ greater than those of $\mathrm{R} 16$ before the onset of the decline. The SPAD data for two QTL introgression lines presented in Fig. 2 indicate that they fell between their recurrent and donor parents in terms of leaf chlorophyll, both before and after the onset of leaf senescence, indicating that the B35 alleles they contain also affected leaf chlorophyll content.

The analysis of the full SPAD data set confirmed the chlorophyll content was affected by genotype as well as leaf number and date of observation, and all interactions of these factors (Table 3). Date and leaf number effects (and their interaction) reflect progressive senescence with time after flowering, which begins earlier in the lower leaves. The genotype and
Table 3 Wald statistics for the effects of genotype, date of observation, leaf number and their interactions on SPAD readings for leaves two and four (from the panicle) for stay-green introgression lines from the 2005-2006 early-onset stress dryland environment

\begin{tabular}{lrrrr}
\hline $\begin{array}{l}\text { Source of } \\
\text { variation }\end{array}$ & $\begin{array}{l}\text { Wald } \\
\text { statistic }\end{array}$ & $d f$ & Wald $/ d f$ & $\begin{array}{l}\text { Chi square } \\
\text { probability }\end{array}$ \\
\hline Genotype & 282.26 & 10 & 28.23 & $<0.001$ \\
Date & $1,972.39$ & 4 & 493.10 & $<0.001$ \\
Leaf & 143.87 & 1 & 143.87 & $<0.001$ \\
Genotype $\times$ date & 74.84 & 40 & 1.87 & $<0.001$ \\
Genotype $\times$ leaf & 26.55 & 10 & 2.66 & 0.003 \\
Date $\times$ leaf & 145.87 & 4 & 36.47 & $<0.001$ \\
Geno $\times$ date $\times$ leaf & 66.76 & 40 & 1.67 & 0.005 \\
\hline
\end{tabular}

genotype $\times$ leaf interactions reflect inherent differences in SPAD readings before the onset of senescence plus the differential rates of senescence seen in Fig. 3. B35 and R 16 were significantly different over the whole course of the measurements and the majority of the QTL introgression lines had significantly higher SPAD readings over the first 20 days of grain filling (Table 4). For example, the mean SPAD reading 5 days after flowering of the introgression lines was 46 whereas the donor parent (B35) and the recurrent parent ( $R$ 16) had readings of 51 and 32, respectively (Table 4). At this stage, all nine introgression lines had significantly higher readings than R 16 and all but three were statistically equal to B35 (Table 4). By about 29 days after flowering, when the senescence was more advanced in the introgression lines, three of the nine were still significantly superior to $\mathrm{R} 16$, although all by this time had SPAD readings that were less than that of B35. Clearly the introgression of the B35 alleles at one or more of stay-green QTL increased the chlorophyll content of the resulting lines, to levels above those of $\mathrm{R} 16$, especially before leaf senescence became a confounding factor, but as in the case of leaf senescence itself, not to the level of the donor parent. Similar results were reported by Xu et al. (2000a), where B35 showed a much higher chlorophyll content $(40.1 \%)$ than that of the senescent parent Tx7000 (16.2\%) at physiological maturity. However, in that case the RIL population progenies exhibited transgressive segregation with chlorophyll values ranging from 9.5 to $59.3 \%$.

In our study, chlorophyll content and \% GLA (visual scoring), based on the data from the second 


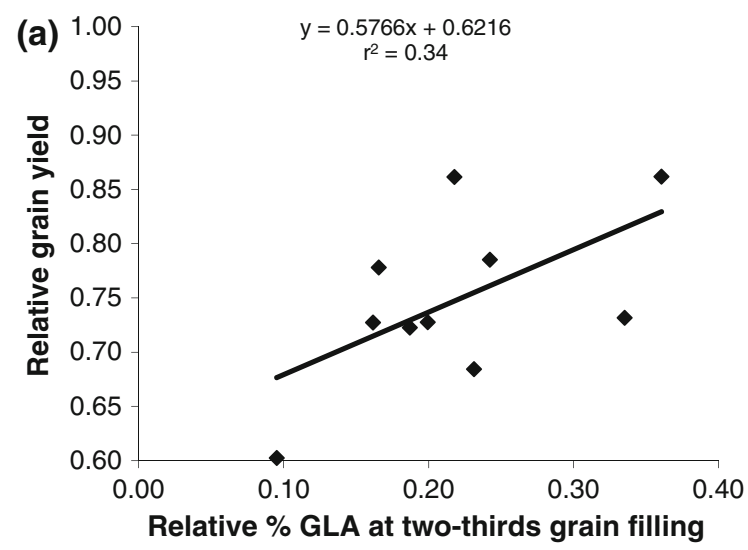

Table 4 SPAD reading (chlorophyll content) for leaves two and four (from the panicle) for the parents and the R 16 staygreen introgression lines during grain filling in the early-onset post-flowering stress environment during 2005-2006

\begin{tabular}{llllll}
\hline Genotype & \multicolumn{5}{l}{ Time from flowering } \\
\cline { 2 - 6 } & 5 days & 15 days & 22 days & 29 days & 36 days \\
\hline B35 & 51 & 50 & 46 & 39 & 22 \\
R 16 & 32 & 30 & 23 & 14 & 4 \\
RSG 04001 & 43 & 39 & 36 & 28 & 12 \\
RSG 04002 & 47 & 34 & 29 & 18 & 5 \\
RSG 04003 & 47 & 37 & 31 & 17 & 5 \\
RSG 04004 & 52 & 49 & 43 & 30 & 13 \\
RSG 04005 & 43 & 39 & 27 & 17 & 7 \\
RSG 04007 & 40 & 34 & 29 & 14 & 6 \\
RSG 04009 & 51 & 44 & 38 & 22 & 6 \\
RSG 04011 & 46 & 38 & 31 & 15 & 2 \\
RSG 04013 & 46 & 37 & 30 & 16 & 6 \\
S.e.d. & 3.3 & 3.3 & 3.3 & 3.3 & 3.3 \\
RSG > R 16 & 9 & 7 & 6 & 3 & 2 \\
\hline
\end{tabular}

${ }^{\mathrm{a}} \mathrm{RSG}>\mathrm{R} 16$ is the number of QTL introgression lines that are significantly $(P<0.05)$ greater than $\mathrm{R} 16$

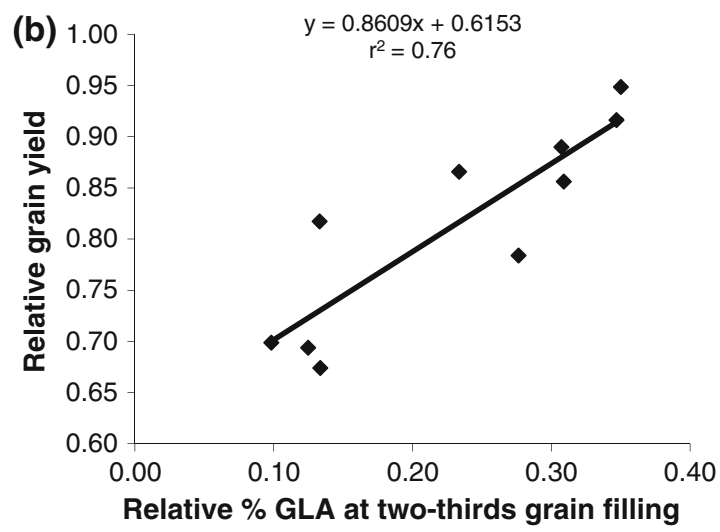

Fig. 3 Relationship between relative (dryland/supplementally irrigated) stay-green expression (\% GLA) at $2 / 3$ grain filling to relative grain yield among $\mathrm{R} 16$ and its backcross derivatives. Figures are for a the 2004-2005 dryland environment and $\mathbf{b}$ the 2005-2006 late-onset stress dryland environment

leaf at 30 days after flowering (when leaf senescence had begun) showed very high correlation $\left(r^{2}=0.93\right.$, $P \leq 0.001)$ in the early-onset stress environment, suggesting a strong relationship between leaf chlorophyll content and green leaf area. Xu et al. (2000a) also reported a significant correlation $\left(r^{2}=0.82, P \leq\right.$ 0.001 ) between stay-green rating and chlorophyll content (SPAD reading). They also reported that the QTLs detected for chlorophyll content and stay-green were overlapping.

Borrell and Hammer (2000) reported strong association between leaf nitrogen content (LNC) at anthesis and grain yield under drought stress. They also suggested that this strong association could be used to screen genotypes for drought tolerance in sorghum breeding programs by measuring LNC at anthesis. Chapman and Barreto (1997) have shown that SPAD

chlorophyll meter can be used to estimate LNC in maize. Studies in sorghum have also shown good correlations between SPAD and specific leaf nitrogen (Borrell and Hammer 2000). In addition, the chlorophyll meter could be used to rate stay-green in breeding lines during the latter half of the grain-filling period (Borrell et al. 1999).

\section{Relationships of leaf senescence and yield}

Delayed leaf senescence (stay-green) in sorghum has been associated with improved grain yield, particularly in environments in which available water during grain filling is not adequate to support potential transpiration (Borrell et al. 2000b). The assumption behind the introgression of the stay-green trait into a senescent line like R 16 is that this will have a positive effect on grain yield under conditions of moisture stress during grain filling by delaying leaf senescence and increasing carbon availability for grain filling, and therefore improving grain size and grain yield.

In the present study, there were significant correlations of relative (dryland environment as a fraction of the supplementally-irrigated environment) \% GLA at 
$2 / 3$ of the grain-filling period to relative grain filling in two of the three comparisons. Percent green leaf area accounted for $56 \%\left(r^{2}=0.56, P<0.05\right)$ of the variation in relative 100 -grain mass in the dryland environment in 2004-2005 and 32\% $\left(r^{2}=0.32\right.$, $P<0.10)$ of the variation in relative 100 -grain mass in the late-onset stress dryland environment in 20052006. In the more severe early-onset stress environment of 2005-2006 there was no relationship of relative \% GLA at $2 / 3$ grain filling and relative 100 -grain mass, largely because few of the introgression lines had a significant green leaf area remaining at that point. Relative, rather than absolute, values of both traits were used as there were considerable differences in yielding ability and plant type among the introgression lines, which (1) reflected differences in the agronomic value of the parents, as the lines were only $\mathrm{BC}_{1}$ or $\mathrm{BC}_{2}$ generation, and (2) were not related to stay-green or its effects. Relative values are an appropriate measure of the ability of a genotype to maintain its normal or non-stress phenotype in the stress environments.

The relationship of a higher relative \% GLA and a greater degree of grain filling translated into a relationship between relative \% GLA and relative grain yield in both the 2004-2005 and the 2005-2006 lateonset stress dryland environments. Differences in the \% GLA of the QTL introgression lines at two-thirds of grain filling accounted for $34 \% \quad\left(r^{2}=0.34\right.$, $P<0.10)$ of the differences in relative grain yield in the 2004-2005 dryland environment and 76\% $\left(r^{2}=0.76, P<0.01\right)$ of the differences in the lateonset stress dryland environment in 2005-2006 (Fig. 3). Similarly, differences in chlorophyll content (SPAD values) accounted for a significant proportion of differences in grain yield $\left(r^{2}=0.42, P<0.05\right)$ at physiological maturity in the early-onset stress environment of 2005-2006. These relationships reflect the importance of maintaining a functional leaf area into the last stages of the grain-filling period, to allow a genotype to fill its grain as nearly as possible to its genetic maximum grain size, and thus increase yields to the ceiling set by the actual grain numbers established at flowering. In a similar study of nine sorghum genotypes varying in stay-green, Borrell et al. (1999) found that grain yield was correlated positively with green leaf area at maturity $(r=0.75, P<0.05)$ and negatively with rate of leaf senescence $(r=0.74$, $P<0.05)$, supporting the hypothesis that sorghum genotypes possessing the stay-green trait have a significant yield advantage under post-anthesis drought stress conditions compared with genotypes not possessing this trait. They also reported that stay-green did not constrain yield when water was not limiting, since no differences in grain yield were observed among eight of nine genotypes under fully-irrigated control conditions. When water was limiting during grain growth, yield accumulation in stay-green genotypes was largely dependent on photo-assimilation in the remaining green leaves. Lower grain yields in the intermediate and senescent genotypes were associated with retention of fewer green leaves, although this reduction was offset to some extent in the intermediate hybrid by utilization of stem reserves for grain filling (Borrell et al. 1999).

\section{Conclusions}

These data demonstrate that stay-green QTLs from the donor parent have been successfully introgressed into the backcross progenies, and are expressing in the genetic background of the recurrent parent R 16 . The majority of the QTL introgression lines had higher leaf chlorophyll content (SPAD reading) both before and during leaf senescence. They also had either a delayed initiation of leaf senescence (supplementally-irrigated environment) or slower rate of loss of \% GLA (post-flowering moisture deficit environments). Reduced leaf senescence (relative \% GLA in the stress/irrigated conditions) was related to higher relative grain yield in two of the three post-flowering stress environments. These results demonstrate the potential gains from marker-assisted selection/backcrossing for enhancing a complex trait like drought tolerance, which is difficult with only phenotypic selection.

Successfully using a MAS program requires several benchmarks of success, including the recovery of the target trait from the donor parent and recovery of recurrent parent phenotype for characters not directly associated with the introgressed target trait. This study demonstrates that a reasonable degree of success has been achieved in the case of the first benchmark, as a number of the QTL introgression lines were significantly more stay-green than $\mathrm{R} 16$, and able to better maintain their relative yield level in the post-flowering stress environment than was R 16 . 
However, none of the QTL introgression lines was as stay-green as B35, which may be only a result of the transfer of selected stay-green QTL rather than the full complement of stay-green QTL in B35. The task now is to complete the backcrossing program to fully recover the $\mathrm{R} 16$ phenotype and to test the effects of the individual stay-green QTLs and the potential gains from pyramiding multiple stay-green QTLs into a common genetic background.

Acknowledgments The authors would like to thank Mr. B. Shivaiah and Mr. M. Kistaiah for the management of the field trials and the collection of large amounts of data involved, Mr. C. Muralidhar for conducting the crossing work and Ms. B. Rekha for the organization and analysis of the data presented in this paper. They would also like to thank Dr. V. Mahalakshmi, Dr. R. T. Folkertsma, Mr. G. Soma Raju, Mr. C. Muralidhar, and Mr. Punna Ramu for their contributions to the marker-assisted backcrossing program that generated the early-generation stay-green QTL introgression lines evaluated in this study. KB sincerely acknowledges the financial support provided during the study period by the Generation Challenge Program (GCP) and the Ethiopian Government. This study was supported with funds from the GCP, and from core funding to ICRISAT from the CGIAR.

Open Access This article is distributed under the terms of the Creative Commons Attribution Noncommercial License which permits any noncommercial use, distribution, and reproduction in any medium, provided the original author(s) and source are credited.

\section{References}

Borrell AK, Hammer GL (2000) Nitrogen dynamics and the physiological basis of stay-green in sorghum. Crop Sci 40:1295-1307

Borrell AK, Bidinger FR, Sunitha K (1999) Stay-green trait associated with yield in recombinant inbred sorghum lines varying in rate of leaf senescence. Int Sorghum Millets Newsl 40:31-34

Borrell AK, Hammer GL, Douglas ACL (2000a) Does maintaining green leaf area in sorghum improve yield under drought? I. Leaf growth and senescence. Crop Sci 40:1026-1037

Borrell AK, Hammer GL, Henzel RG (2000b) Does maintaining green leaf area in sorghum improve yield under drought? II. Dry matter production and yield. Crop Sci 40:1037-1048

Chapman SC, Barreto MJ (1997) Using a chlorophyll meter to estimate specific leaf nitrogen of tropical maize during vegetative growth. Agron J 89:557-562

Crasta RR, Xu W, Rosenow DT, Mullet JE, Nguyen HT (1999) Mapping of post-flowering drought resistance traits in grain sorghum: association of QTLs influencing premature senescence and maturity. Mol Gen Genet 262:579-588. doi: $10.1007 / \mathrm{s} 004380051120$
Dwyer LM, Tollenaar M, Houwing L (1991) A non-destructive method to monitor leaf greenness in corn. Can J Plant Sci 71:505-509

FAO (2006) FAO statistics data base (FAOSTAT) for 2005. http://faostat.fao.org. Cited 15 Feb 2007

Harris K, Subudhi PK, Borrell A, Jordan D, Rosenow D, Nguyen H, Klein P, Klein R, Mullet J (2007) Sorghum stay-green QTL individually reduce post-flowering drought-induced leaf senescence. J Exp Bot 58:327-338. doi:10.1093/jxb/erl225

Hash CT, Bhasker Raj AG, Lindup S, Sharma A, Beniwal CR, Folkertsma RT, Mahalakshmi V, Zerbini E, Blümmel M (2003) Opportunities for marker-assisted selection (MAS) to improve the feed quality of crop residues in pearl millet and sorghum. Field Crops Res 84:79-88. doi:10.1016/ S0378-4290(03)00142-4

Haussmann BIG, Mahalakshmi V, Reddy BVS, Seetharama N, Hash CT, Geiger HH (2002) QTL mapping of stay-green in two sorghum recombinant inbred populations. Theor Appl Genet 106:133-142

Jordan DR, Tao T, Godwin ID, Henzell RG, Cooper M, McIntyre CL (2003) Prediction of hybrid performance in grain sorghum using RFLP markers. Theor Appl Genet 106:559-567

Kebede H, Subudhi PK, Rosenow DT, Nguyen HT (2001) Quantitative trait loci influencing drought tolerance in grain sorghum (Sorghum bicolor (L.) Moench). Theor Appl Genet 103:266-276. doi:10.1007/s001220100541

Mahalakshmi V, Bidinger FR (2002) Evaluation of staygreen sorghum germplasm lines at ICRISAT. Crop Sci 42:965-974

McBee GG (1984) Relation of senescence, non senescence, kernel maturity to carbohydrate metabolism in sorghum. In: Mughogho LK (ed) Sorghum root and stalk diseases: a critical review. Proceedings of the consultative discussion of Research Needs and Strategies for Control of Sorghum Root and Stalk Diseases, Bellagio, Italy, 27 Nov-2 Dec, 1983. ICRISAT, Patancheru, pp 119-129

Rajcan I, Tollenaar M (1999) Source: sink ratio and leaf senescence in maize: II. Nitrogen metabolism during grain filling. Field Crops Res 60:255-265. doi:10.1016/S03784290(98)00143-9

Rosenow D, Quisenberry JE, Wendt CE, Clark LE (1983) Drought tolerant sorghum and cotton germplasm. Agric Water Manag 7:207-222. doi:10.1016/0378-3774(83) 90084-7

Sanchez AC, Subudhi PK, Rosenow DT, Nguyen HT (2002) Mapping QTLs associated with drought resistance in sorghum (Sorghum bicolor (L.) Moench). Plant Mol Biol 48:713-726. doi:10.1023/A:1014894130270

Subudhi PK, Rosenow DT, Nguyen HT (2000) Quantitative trait loci for the stay-green trait in sorghum (Sorghum bicolor L. Moench): consistency across genetic backgrounds and environments. Theor Appl Genet 101:733-741. doi:10.1007/s001220051538

Tao YZ, Henzell RG, Jordan DR, McIntyre CL (2000) Identification of genomic regions associated with stay-green in sorghum by testing RILs in multiple environments. Theor Appl Genet 100:1225-1232. doi:10.1007/s001220051428

Thomas H, Howarth CJ (2000) Five ways to stay green. J Exp Bot 51:29-337. doi:10.1093/jexbot/51.342.29 
Thomas H, Rogers LJ (1990) Turning over an old leaf. Univ Wales Rev Sci Technol 6:29-38

Thomas H, Smart CM (1993) Crops that stay green. Ann Appl Biol 123:193-233. doi:10.1111/j.1744-7348.1993. tb04086.x

Tuinstra MR, Grote EM, Goldsbrough PB, Ejeta G (1996) Identification of quantitative trait loci associated with pre-flowering drought tolerance in sorghum. Crop Sci 36:1337-1344

Tuinstra MR, Grote EM, Goldsbrough PB, Ejeta G (1997) Genetic analysis of post-flowering drought tolerance and components of grain development in Sorghum bicolor (L.) Moench. Mol Breed 3:439-448. doi:10.1023/A:1009673 126345

Tuinstra MR, Ejeta G, Goldsbrough PR (1998) Evaluation of near-isogenic sorghum lines contrasting for QTL markers associated with drought tolerance. Crop Sci 38:835-842 van Oosterom E, Jayachandran R, Bidinger FR (1996) Diallel analysis of the stay-green trait and its components in sorghum. Crop Sci 36:549-555

Walulu RS, Rosenow DT, Wester DM, Nguyen HT (1994) Inheritance of stay-green trait in sorghum. Crop Sci 34:970-972

Xu W, Rosenow DT, Nguyen HT (2000a) Stay-green trait in grain sorghum: relationship between visual rating and leaf chlorophyll concentration. Plant Breed 119:365-367. doi:10.1046/j.1439-0523.2000.00506.x

Xu W, Subudhi PK, Crasta OR, Rosenow DT, Mullet JE, Nguyen HT (2000b) Molecular mapping of QTLs conferring stay-green in grain sorghum (Sorghum bicolor L. Moench). Genome 43:461-469. doi:10.1139/gen-43-3-461 